\title{
Solid Malignancies Among Patients in the Wegener's Granulomatosis Etanercept Trial
}

\author{
John H. Stone, ${ }^{1}$ Janet T. Holbrook, ${ }^{1}$ Matthew A. Marriott, ${ }^{1}$ Andrea K. Tibbs, ${ }^{1}$ \\ Lourdes P. Sejismundo, ${ }^{1}$ Y.-I. Min, ${ }^{1}$ Ulrich Specks, ${ }^{2}$ Peter A. Merkel, ${ }^{3}$ Robert Spiera, \\ John C. Davis, ${ }^{5}$ E. William St.Clair, ${ }^{6}$ W. Joseph McCune, ${ }^{7}$ Steven R. Ytterberg, ${ }^{2}$ \\ Nancy B. Allen, ${ }^{6}$ and Gary S. Hoffman, ${ }^{8}$ for the \\ Wegener's Granulomatosis Etanercept Trial Research Group
}

Objective. Etanercept is a soluble fusion protein designed to inhibit tumor necrosis factor (TNF). During the Wegener's Granulomatosis Etanercept Trial (WGET), a placebo-controlled trial of etanercept given in addition to standard therapy for remission induction and maintenance, more solid malignancies were observed in the etanercept group than in the group treated with standard therapy alone. This study was undertaken to further explore the potential association between

Supported by the National Institute of Arthritis and Musculoskeletal and Skin Diseases (contract N01-AR-9-2240), by the FDA/ Office of Orphan Products (grant FD-R-001652-01), by NIAMS grants K24-AR-049185-01, K24-AR-2224-01A1, and K24-AR-02126-04 (to Drs. Stone, Merkel, and St.Clair), by General Clinical Research Center grants M01-RR0-2719 (to Johns Hopkins University School of Medicine), M01-RR0-00533 (to Boston University), M01-RR0-0042 (to the University of Michigan), and M01-RR-30 (to Duke University) from the National Center for Research Resources, and by Amgen Corporation, Thousand Oaks, California. Dr. Stone is a Hugh and Renna Cosner Scholar in the Johns Hopkins Bayview Center for Innovative Medicine.

${ }^{1}$ John H. Stone, MD, MPH, Janet T. Holbrook, PhD, MPH, Matthew A. Marriott, PA-C, Andrea K. Tibbs, BS, L. P. Sejismundo, MD, Y.-I. Min, MD: Johns Hopkins University, Baltimore, Maryland; ${ }^{2}$ Ulrich Specks, MD, Steven R.Ytterberg, MD: Mayo Clinic, Rochester, Minnesota; ${ }^{3}$ Peter A. Merkel, MD, MPH: Boston University, Boston, Massachusetts; ${ }^{4}$ Robert Spiera, MD: Beth Israel Medical Center, New York, New York; ${ }^{5}$ John C. Davis, MD, MPH: University of California, San Francisco; ${ }^{6}$ E. William St.Clair, MD, Nancy B. Allen, MD: Duke University, Durham, North Carolina; ${ }^{7}$ Joseph McCune, MD, University of Michigan, Ann Arbor; ${ }^{8}$ Gary S. Hoffman, MD: Cleveland Clinic Foundation, Cleveland, Ohio.

Dr. St.Clair has received consulting fees or honoraria (less than $\$ 10,000$ per year) from Centocor, Human Genome Sciences, and Genentech and consulting fees or honoraria (more than $\$ 10,000$ per year) from Cellective Therapeutics.

Address correspondence and reprint requests to John $\mathrm{H}$ Stone, MD, MPH, The Johns Hopkins Vasculitis Center, 5501 Hopkins Bayview Circle, JHAAC 1B.23, Baltimore, MD 21224. E-mail: jstone@jhmi.edu.

Submitted for publication July 17, 2005; accepted in revised form February 15, 2006.
anti-TNF therapy and the development of malignancy in these patients.

Methods. One hundred eighty patients with active WG were enrolled and followed up for a median of 27 months. At enrollment, disease characteristics, treatment history, specific medical history items, and information about previous WG treatments and risk factors for malignancy were recorded. During the trial, the occurrence of malignancies and other adverse events was recorded prospectively.

Results. All 6 solid malignancies observed during the WGET occurred in the etanercept group $(P=0.01$ versus placebo group); based on a comparison of ageand sex-specific incidence rates, 1.92 solid malignancies would have been expected in this group. The solid malignancies included 2 cases of mucinous adenocarcinoma of the colon, 1 each of metastatic cholangiocarcinoma, renal cell carcinoma, and breast carcinoma, and 1 recurrent liposarcoma. There were no differences between the 2 treatment groups in sex distribution, disease severity, personal or family history of cancer, or tobacco and alcohol use. The etanercept group was older at baseline and less likely to be newly diagnosed with WG at the time of randomization. Patients who developed solid tumors were older than patients who did not. All etanercept-treated patients who developed solid tumors were also treated with cyclophosphamide during the trial. However, there were no differences between the groups in the amount of cyclophosphamide received during the trial or the percentage who had received cyclophosphamide before enrollment. There were also no differences in the mean duration of daily cyclophosphamide therapy or the maximum daily cyclophosphamide dosage before enrollment.

Conclusion. Data from the WGET, the first sub- 
stantial reported experience of the combined use of etanercept and cyclophosphamide in the treatment of WG, indicate that the combination of TNF inhibition and cyclophosphamide may heighten the risk of cancer beyond that observed with cyclophosphamide alone.

Tumor necrosis factor (TNF) inhibition now plays a major role in the treatment of several inflammatory conditions, particularly forms of inflammatory arthritis, psoriasis, and Crohn's disease (1-5). The term "tumor necrosis factor" was derived from the molecule's ability to kill transplanted tumors in mice (6). Thus, a theoretical concern has been that TNF inhibition might lead to an excess of malignancies through several mechanisms, such as permitting tumors to arise de novo with greater frequency, diminishing immunosurveillance for subclinical tumors, and accelerating the growth of established tumors.

To date, the concern about an increased potential for cancer among patients treated with TNF inhibitors has centered primarily around lymphomas (7-9). Compared with the National Institutes of Health Surveillance Epidemiology and End Results (SEER) database (10), the standardized incidence ratios for the development of lymphoma have ranged from 2.3 to 6.4 in clinical trials of TNF inhibitors (11). In 2004, the Food and Drug Administration began requiring that a warning about a possible increased risk of lymphoma be included in the prescribing information (labels) of the 3 currently available TNF inhibitors, etanercept (Enbrel), infliximab (Remicade), and adalimumab (Humira).

In addition to the concern about lymphoma risk, case reports and publications of small case series have described potential associations between TNF inhibitor treatment and a variety of other malignancies, including leukemia $(12,13)$, T cell lymphoma (14), squamous cell carcinoma of the skin $(15,16)$, and Kaposi's sarcoma (17). In general, interpretation of the significance of these results has been hampered by several factors: the relatively isolated nature of such reports, the usual presence of other risk factors for the development of malignancies (e.g., the concomitant use of other immunosuppressive agents or, in the case of squamous cell carcinoma of the skin, histories of substantial sun exposure), or the potentially higher risk of malignancy conferred by underlying disease, such as rheumatoid arthritis (RA).

The Wegener's Granulomatosis Etanercept Trial (WGET) (18) was a randomized, double-blind, placebocontrolled trial of etanercept added to standard therapy for the induction and maintenance of disease remission.
Details of the trial design and the overall trial results have been reported previously (18-20). Members of the WGET Research Group are listed in Appendix A. The WGET was the first trial of relatively large size in which substantial numbers of patients were treated simultaneously with cyclophosphamide and a TNF inhibitor. Because solid malignancies were found to occur at higher frequency in the group treated with etanercept in addition to standard therapy, we investigated these cases in greater detail and examined more closely the potential association between TNF inhibition and malignancy.

\section{PATIENTS AND METHODS}

The WGET was conducted to test the hypothesis that etanercept, a soluble inhibitor of TNF, was more effective than placebo in the maintenance of disease remission. The experimental medication (etanercept or placebo) was initiated along with conventional therapy, at a dose of $25 \mathrm{mg}$ administered subcutaneously twice weekly, at the start of the remission induction phase. The experimental medication (provided by Amgen Corporation, Thousand Oaks, CA) was then continued during remission as conventional therapy was tapered (19). The primary outcome measure in the WGET was maintenance of disease remission (i.e., a Birmingham Vasculitis Activity Score for WG [21] of 0 for 6 months) with the experimental medication. A total of 180 patients with active WG (either newly diagnosed or recurrent) were enrolled and followed up for a median of 27 months. All patients stopped the experimental medication on a common closeout date, followed by a 6-month observation period during which they were treated according to best medical judgment. Patients with either severe or limited WG were eligible for the trial. Malignancy within the previous 5 years was an exclusion criterion, with the exception of basal or squamous cell carcinomas of the skin for which patients had undergone curative surgery (19). The treatment schema is shown in Figure 1.

Severe disease. Severe WG was defined as disease that posed an immediate threat to the patient's life or to the function of a vital organ $(19,21)$. Patients with severe WG began cyclophosphamide at an initial dosage of $2 \mathrm{mg} / \mathrm{kg} / \mathrm{day}$ (adjusted for renal dysfunction [19]) and prednisone at 0.5-1 $\mathrm{mg} / \mathrm{kg} /$ day. At the start of therapy, methylprednisolone (1 $\mathrm{gm} /$ day for 3 days) could also be administered at the investigator's discretion. Tapering of the prednisone dosage was started after 1 month, with the goal of discontinuing prednisone within 6 months of randomization.

Limited disease. Limited disease, which did not pose a threat to either life or vital organ function at the time of enrollment, was treated with methotrexate $(0.25 \mathrm{mg} / \mathrm{kg} / \mathrm{week}$, increased over 2 weeks to a maximum of $25 \mathrm{mg} / \mathrm{week}$ ) and glucocorticoids. Patients with limited disease did not receive methylprednisolone pulses, but their glucocorticoid regimens were otherwise identical to those of patients with severe disease.

Tapering of immunosuppressive treatment regimens. Patients in whom disease remission was achieved after a minimum of 3 months of cyclophosphamide treatment discon- 


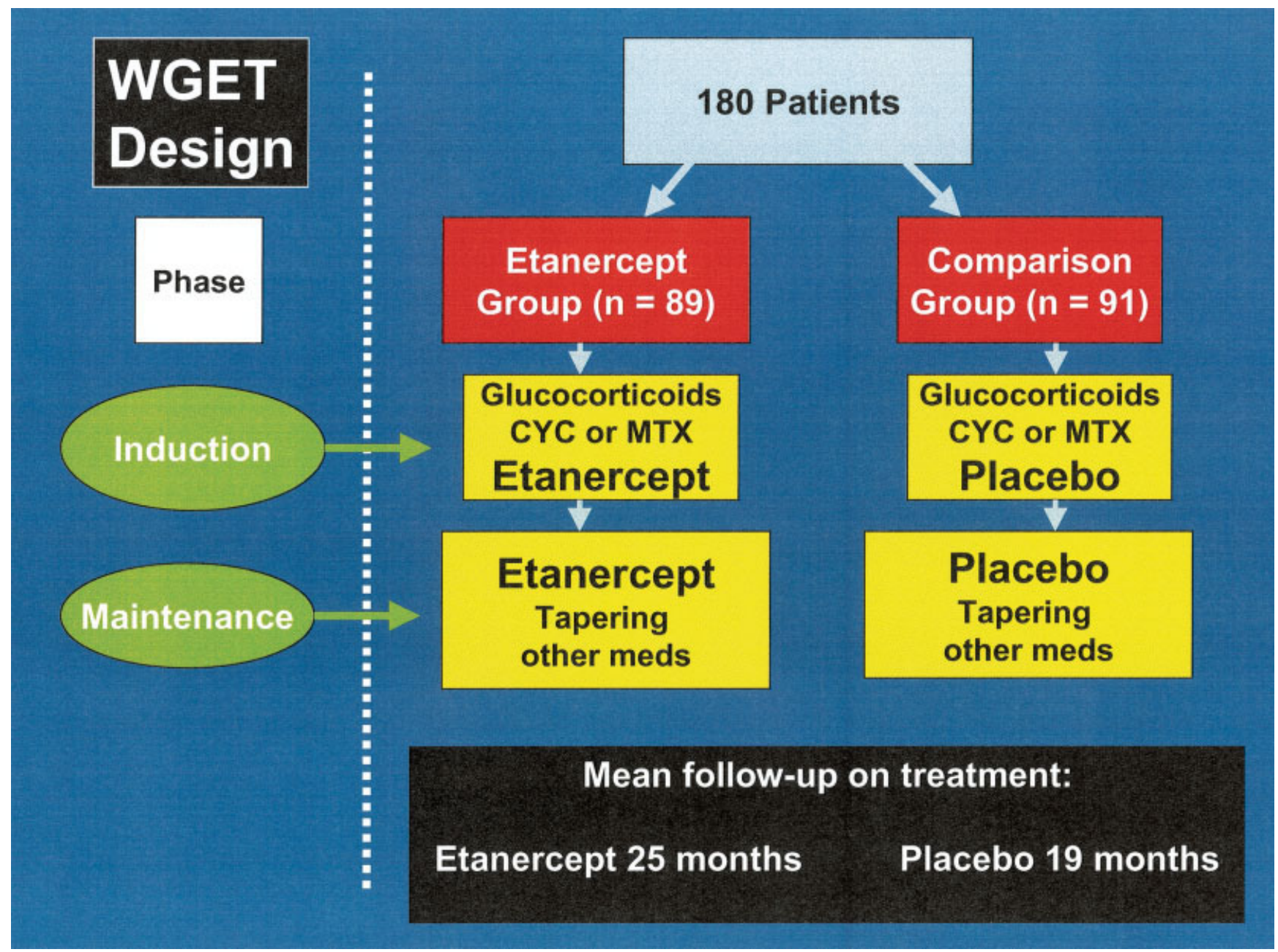

Figure 1. Treatment schema in the Wegener's Granulomatosis Etancercept Trial (WGET). CYC = cyclophosphamide; MTX $=$ methotrexate.

tinued that medication and started methotrexate (maximum dose $25 \mathrm{mg} /$ week). Patients with serum creatinine levels $\geq 2.0$ $\mathrm{mg} / \mathrm{dl}$ were treated with azathioprine $(2 \mathrm{mg} / \mathrm{kg} / \mathrm{day}$, up to a maximum of $200 \mathrm{mg} /$ day) instead of methotrexate during the remission maintenance phase. After 1 year of remission, methotrexate and azathioprine were tapered by $2.5 \mathrm{mg} / \mathrm{month}$ and $25 \mathrm{mg} / \mathrm{month}$, respectively, with the goal of discontinuing both medications completely.

Data collection. At enrollment, detailed medical histories, which included questions relevant to the risk of malignancy, were obtained on all patients. Disease characteristics, treatment history, and specific medical history items were recorded on a baseline medical history form. Information about the duration of use and maximum dosage of all medications used to treat WG was recorded, as were data on family history and on patient history of malignancy and tobacco and alcohol use.

Reporting of adverse events. All adverse events (graded according to a modified version of the National
Cancer Institute Graded Toxicity Scale [22]) were recorded in adverse events logs. Adverse events of grade 3 or higher, corresponding to the categories of severe, life-threatening, or fatal, were reported within 24 hours, on separate forms for serious adverse events.

Confirmation of malignancies. Histopathologic diagnoses of solid malignancies were confirmed in all cases by reviewing reports of the original biopsies. For patients who died and underwent autopsies, postmortem reports were also reviewed. Comparisons between treatment groups were limited to events observed during the blinded treatment trial because these data were less likely to be influenced by observer bias and knowledge of prior results regarding the incidence of cancer during the trial.

Statistical analysis. Analyses were performed using SAS version 8.0 (SAS Institute, Cary, NC). Differences in patient characteristics between the 2 treatment groups were evaluated by Wilcoxon's rank sum test for continuous variables, and by either chi-square or Fisher's exact test for 
categorical variables. The incidence rate for malignancies was calculated by dividing the number of events by the total patient-years of observation. The standardized incidence ratio ([observed/expected cases] $\times 100)$ for the solid malignancies observed was calculated by comparison of the incidence rate in the etanercept group with the age- and sex-specific incidence rate in the SEER database (10); this database includes all invasive cancers plus urinary bladder cancer and breast carcinoma in situ.

\section{RESULTS}

Solid malignancies during experimental treatment. During the period of experimental treatment, 6 solid malignancies were observed in the etanercept group, compared with 0 in the control group $(P=0.01)$. All patients who developed a malignancy while receiving experimental treatment also received cyclophosphamide as therapy for WG during the trial. Among the 62 patients assigned initially to receive etanercept and cyclophosphamide, therefore, 9.7\% developed solid malignancies over a median followup of just over 2 years. The essential features of these 6 patients who developed malignancies are shown in Table 1. Brief case vignettes are provided below.

Patient 1. Patient 1, a 60-year-old man, was diagnosed as having WG and enrolled in the WGET following presentation with constitutional symptoms, pulmonary nodules, a hilar mass, glomerulonephritis, and antineutrophil cytoplasmic antibodies directed against proteinase 3 . His condition responded dramatically to the institution of WG treatment, and the disease entered remission. A followup computed tomography (CT) scan revealed resolution of the pulmonary findings (lung nodules, hilar mass) that had been present at baseline. Nine months after randomization, the patient presented with new scapular pain and right upper quadrant pain. Evaluation revealed hepatic lesions suspicious for metastatic cancer. Adenocarcinoma of unknown primary was diagnosed on liver biopsy. The experimental medication (etanercept) was stopped. The patient declined treatment for his malignancy and died 1 month later. A postmortem examination revealed adenocarcinoma of the gallbladder, metastatic to the liver, bone, and lungs.

Patient 2. Patient 2, a 51-year-old woman with severe WG, was enrolled in the WGET and received 9 months of etanercept plus cyclophosphamide therapy before switching to a remission maintenance regimen of etanercept plus methotrexate. Thirteen months after randomization she reported periumbilical pain. A CT scan of the abdomen revealed a $2.9-\mathrm{cm}$ mass within the upper pole of the right kidney. The patient underwent a partial nephrectomy. Histopathologic analysis showed a renal cell carcinoma confined to the renal capsule. The patient's experimental medication (etanercept) was discontinued following the diagnosis of her malignancy, and the methotrexate dosage was reduced. Thirty months after her tumor resection, the patient remained tumor-free.

Patient 3. Patient 3, a 73-year-old man, had undergone resection of a left arm liposarcoma 10 years before enrollment. Following his diagnosis of WG, characterized by multiple pulmonary nodules, sinus disease, livedo reticularis, and episcleritis, the patient was enrolled in the WGET. He received 3 months of etanercept plus cyclophosphamide therapy before switching to etanercept plus azathioprine. Five months after enrollment, the patient noted a mass on his left arm at the site of his previous liposarcoma. Biopsy confirmed a recurrence of malignancy, and he was treated with wide resection of the tumor. The patient's experimental medication (etanercept) was discontinued, but he continued to take azathioprine and low-dose prednisone. His current status is not known.

Patient 4. Patient 4, a 65-year-old woman with severe WG, was enrolled in the WGET. Rapid control of her disease was achieved with cyclophosphamide, glucocorticoids, and etanercept. After 6 months of etanercept plus cyclophosphamide treatment, the treatment was switched to etanercept plus azathioprine for remission maintenance. Thirty months after enrollment, the patient was noted to have a microcytic anemia. At colonoscopy, a 5-cm mass at the proximal ascending colon was detected. Biopsy revealed a moderately differentiated mucinous adenocarcinoma. The experimental medication (etanercept) was discontinued, and the patient underwent resection of the tumor. At surgery, the cancer was found to have extended through the muscularis propria into the pericolonic soft tissue. Three of 24 lymph nodes were positive for tumor. The patient began chemotherapy for her adenocarcinoma (G2N1T3) of the colon. Of note, the patient had undergone a screening colonoscopy, with normal results, just prior to WGET enrollment.

Patient 5. Patient 5, a 55-year-old woman with a 35 pack-year smoking history, had been enrolled in the WGET when she presented with a recurrence of WG marked by pulmonary disease despite methotrexate treatment. Thirty-one months after randomization, following the detection of a breast lump, the patient was diagnosed as having a poorly differentiated, infiltrating ductal carcinoma. Her experimental medication (etan- 


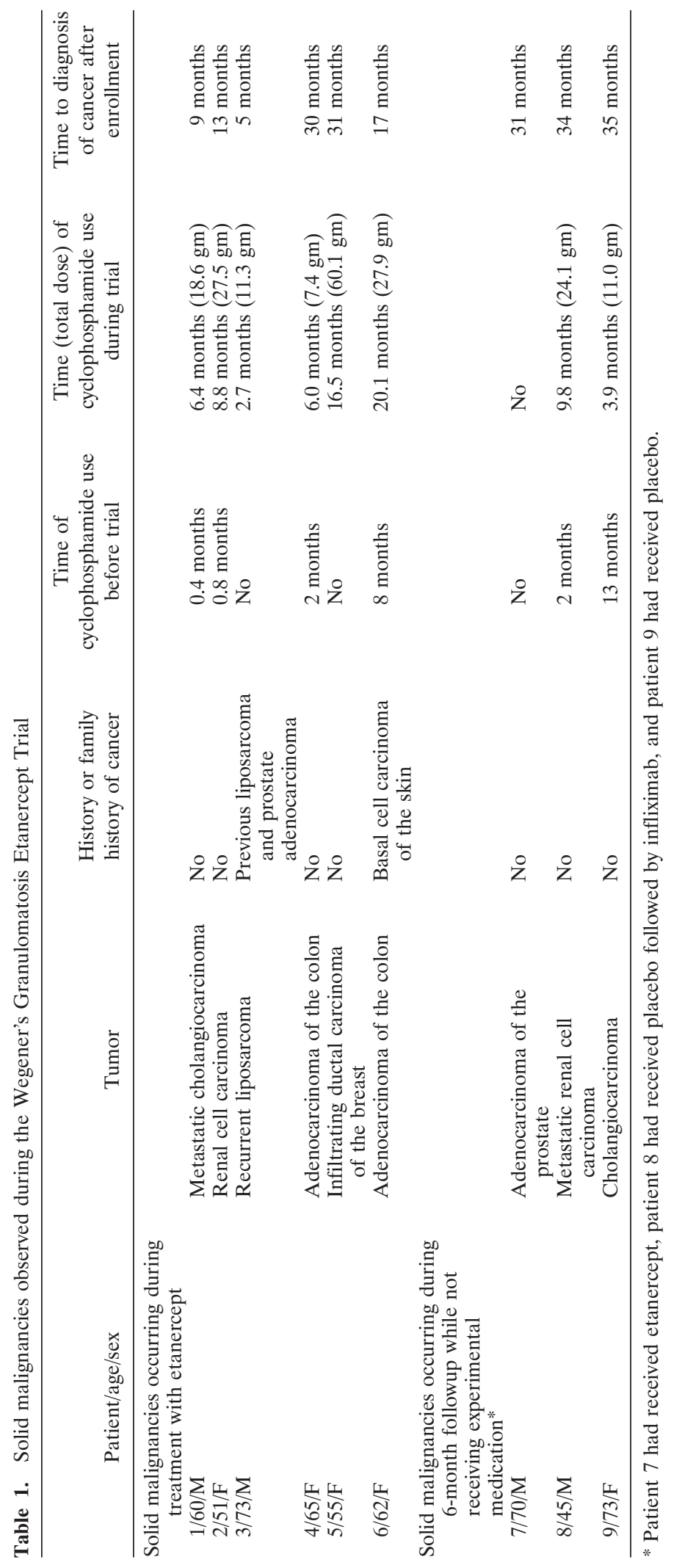


Table 2. Baseline characteristics of patients in the etanercept group versus the control group

\begin{tabular}{|c|c|c|c|c|}
\hline & Control $(\mathrm{n}=91)$ & $\begin{array}{l}\text { Etanercept } \\
(\mathrm{n}=89)\end{array}$ & Total $(\mathrm{n}=180)$ & $\begin{array}{l}P \text {, control } \\
\text { vs. etanercept }\end{array}$ \\
\hline Age, mean \pm SD (range) years & $47.5 \pm 16.5(14-83)$ & $52.4 \pm 13.9(16-79)$ & $49.9 \pm 15.4(14-83)$ & 0.01 \\
\hline Male/female, no. (\%) & $52(57.1) / 39(42.9)$ & $56(62.9) / 33(37.1)$ & $108(60.0) / 72(40.0)$ & 0.43 \\
\hline Limited/severe disease, no. (\%) & $25(27.5) / 66(72.5)$ & $27(30.3) / 62(69.7)$ & $52(28.9) / 128(71.1)$ & 0.67 \\
\hline Newly diagnosed, no. (\%) & $49(53.9)$ & $31(34.8)$ & $80(44.4)$ & 0.01 \\
\hline $\begin{array}{l}\text { Months since onset of symptoms, median } \\
\text { (interquartile range) }\end{array}$ & $12(4-43)$ & $25(7-56)$ & $17(5-50)$ & 0.03 \\
\hline Previous history of cancer, no. $(\%)^{*}$ & $6(6.6)$ & $13(14.6)$ & $19(10.6)$ & 0.08 \\
\hline Family history of cancer, no. (\%) & $20(22.0)$ & $14(15.7)$ & $34(18.9)$ & 0.28 \\
\hline \multicolumn{5}{|l|}{ Tobacco use } \\
\hline Current use, no. (\%) & $2(2.2)$ & $4(4.5)$ & $6(3.3)$ & 0.39 \\
\hline No. of cigarettes/day, mean \pm SD & $22.2 \pm 13.8$ & $16.9 \pm 11.9$ & $19.1 \pm 12.9$ & 0.07 \\
\hline \multicolumn{5}{|l|}{ Alcohol consumption } \\
\hline$<1$ serving/ $\geq 1$ serving of alcohol/month, no. $(\%)$ & $67(73.6) / 24(26.4)$ & $61(68.5) / 28(31.5)$ & $128(71.1) / 52(28.8)$ & 0.45 \\
\hline
\end{tabular}

* Malignancies diagnosed before trial enrollment were as follows: in the control group, melanoma and basal cell carcinoma (both in 1 patient), lymphoma (1 patient), basal cell carcinoma (1 patient), vulvar carcinoma in situ (1 patient), and rectal-skin (precise type not noted) (1 patient); in the etanercept group, prostate ( 2 patients), colon (3 patients), basal cell carcinoma ( 3 patients), skin (1 patient), breast ( 2 patients), bladder (1 patient), and other (1 patient).

ercept) was discontinued. She underwent lumpectomy and axillary lymph node dissection, and the carcinoma was found to have spread to the regional lymph nodes (staging: G3T2N1). The patient experienced multiple complications of chemotherapy and died of cardiac arrest.

Patient 6. Patient 6, a 62-year-old woman with a longstanding history of WG, was enrolled in the WGET when she presented with worsening skin lesions, new large-joint migratory arthralgias, mouth ulcers, and microscopic hematuria. Prior to WGET enrollment, treatment for active disease had included a 240-day course of cyclophosphamide. Seventeen months after enrollment, the patient developed a microcytic anemia. Colonoscopy and biopsies revealed 3 separate mucinous adenocarcinomas in the ascending colon. The experimental medication (etanercept) was discontinued, and the patient underwent a right hemicolectomy. The areas of malignancy were contained, and no additional treatment was required.

Solid malignancies during followup. Solid malignancies were detected in 3 additional patients during the 6-month observation period after the blinded treatment trial (Table 1). A grade 4 adenocarcinoma of the prostate was diagnosed in a 70-year-old man who had been in the etanercept group, a cholangiocarcinoma was diagnosed in a 73-year-old woman who had been treated with placebo, and a metastatic renal cell carcinoma was diagnosed in a 45-year-old man originally assigned to the placebo group who had discontinued experimental therapy because of 2 severe flares and then received infliximab off-label for 14 months prior to his cancer diagnosis.

Other types of malignancy. No hematopoietic malignancies were observed during the WGET. There was no difference between treatment groups in the occurrence of cutaneous basal or squamous cell carcinomas ( 3 patients in the etanercept group, 3 in the placebo group). One patient in the etanercept group had 2 separate diagnoses of basal cell carcinomas $\sim 4$ months apart.

Baseline demographic characteristics and risk factors for malignancy. The demographic features of the etanercept and control groups at enrollment are shown in Table 2. The groups were not different at baseline with regard to sex distribution, disease severity, personal or family history of cancer, or tobacco and alcohol use. Patients in the etanercept group were older (mean \pm SD age $52.4 \pm 13.9$ years versus $47.5 \pm 16.5$ years; $P=0.01$ ) and less likely to be newly diagnosed (31 [34.8\%] versus 49 [53.9\%]; $P=0.01$ ) than those in the control group. Patients who developed solid malignancies during the trial were older than patients who did not (mean age 61 years versus 50 years; $P=0.05$ ) and older at the time their WG symptoms initially began (mean 59 years versus 45 years; $P=0.03$ ). Other demographic and WG disease characteristics were similar among patients who developed solid malignancies and those who did not (Table 3). 
Table 3. Characteristics of the patients who did and those who did not develop solid malignancies during the WGET*

\begin{tabular}{|c|c|c|c|}
\hline & $\begin{array}{l}\text { No solid malignancy } \\
\qquad(\mathrm{n}=174)\end{array}$ & $\begin{array}{l}\text { Solid malignancy } \\
\qquad(\mathrm{n}=6)\end{array}$ & $P \dagger$ \\
\hline \multicolumn{4}{|l|}{ Treatment assignment } \\
\hline Etanercept, no. (\%) & $83(48)$ & $6(100)$ & 0.01 \\
\hline Control, no. $(\%)$ & $91(52)$ & $0(0)$ & \\
\hline Months of treatment, median (IQR) & $21(13-33)$ & $15(8-33)$ & 0.50 \\
\hline Age, mean $\pm \mathrm{SD}$ (range) years & $50 \pm 16(14-83)$ & $61 \pm 8(42-73)$ & 0.05 \\
\hline Male/female, no. (\%) & $106(61) / 68(39)$ & $2(33) / 4(67)$ & 0.22 \\
\hline Limited/severe disease, no. (\%) & $50(29) / 124(71)$ & $2(33) / 4(67)$ & 1.00 \\
\hline Newly diagnosed, no. (\%) & $77(44)$ & $3(50)$ & 1.00 \\
\hline Age at onset of symptoms, mean \pm SD years & $45 \pm 18$ & $59 \pm 8$ & 0.03 \\
\hline Prior treatment with immunosuppressive drugs, no. $(\%)$ & $100(57)$ & $3(50)$ & 1.00 \\
\hline Previous history of cancer, no. $(\%) \ddagger$ & $16(9)$ & $2(33)$ & 0.59 \\
\hline Family history of cancer, no. (\%) & $34(20)$ & $0(0)$ & 0.60 \\
\hline Ever treated for Wegener's granulomatosis, no. (\%) & $151(87)$ & $6(100)$ & 1.00 \\
\hline \multicolumn{4}{|l|}{ Cyclophosphamide treatment, no. $(\%)$} \\
\hline Ever used, daily or intermittent & $128(74)$ & $4(67)$ & 0.69 \\
\hline During WGET & $135(78)$ & $6(100)$ & 0.34 \\
\hline \multicolumn{4}{|l|}{ Methotrexate treatment, no. $(\%)$} \\
\hline Ever used, oral or SC or IM & $64(37)$ & $3(50)$ & 0.67 \\
\hline During WGET & 134 (77) & $3(50)$ & 0.15 \\
\hline \multicolumn{4}{|l|}{ Azathioprine treatment, no. $(\%)$} \\
\hline Ever used & $20(11)$ & $17(1)$ & 0.53 \\
\hline During WGET & $47(27)$ & $50(3)$ & 0.35 \\
\hline Current tobacco use, no. (\%) & $6(3)$ & $0(0)$ & 1.00 \\
\hline
\end{tabular}

* WGET $=$ Wegener's Granulomatosis Etanercept Trial; IQR $=$ interquartile range; $\mathrm{SC}=$ subcutaneous; IM = intramuscular.

$\dagger$ By chi-square or Fisher's exact test for categorical data, and Wilcoxon's rank sum test for continuous data.

$\ddagger$ Previous history of cancer was as follows: in the no solid malignancy group, prostate (1 patient), colon ( 3 patients), melanoma and basal cell (1 patient), skin (1 patient), breast ( 2 patients), precancerous or cancerous skin lesion removed ( 1 patient), lymphoma (1 patient), rectal-skin (1 patient), bladder (1 patient), basal cell ( 3 patients), and vulvar carcinoma in situ (1 patient); in the solid malignancy group, prostate (1 patient), basal cell carcinoma (1 patient).

Treatment before WGET enrollment. The patients' immunosuppressive treatment histories both before WGET enrollment and during the trial are shown in Table 4. There was no significant difference between the groups in the percentages of patients who had received cyclophosphamide before trial enrollment (78.7\% of the etanercept-treated patients versus $68.1 \%$ of the placebo-treated patients; $P=0.11$ ). There were also no significant differences in the percentages of patients who had ever received daily cyclophosphamide $(74.2 \%$ versus $65.9 \%$ in the etanercept and the placebo groups, respectively; $P=0.23$ ), the mean duration of daily cyclophosphamide therapy (60 days versus 73 days, respectively; $P=0.30$ ), or the maximum daily cyclophosphamide dosage (140.2 mg versus $151.5 \mathrm{mg}$, respectively; $P=0.28$ ). Similarly, there were no significant differences between the 2 groups in the use of methotrexate or azathioprine before trial enrollment. There were also no differences in the percentage of patients treated with cyclophosphamide, methotrexate, or azathioprine between the group of patients who were diagnosed as having solid malignancies during the trial and those who were not (Table 3 ).

Treatment during the WGET. Among the patients randomized to receive etanercept, the median duration of treatment with that medication was 25 months (interquartile range 12-33 months). There were no significant differences in the percentages of patients treated with cyclophosphamide during the trial $(76.4 \%$ in the etanercept group, $80.2 \%$ in the placebo group; $P=0.54)$, the median time of treatment with cyclophosphamide (6 months in both groups), or the cumulative cyclophosphamide dose (19 gm versus $18 \mathrm{gm} ; P=$ $0.90)$. There were also no significant differences in the use of either methotrexate or azathioprine during the trial (Table 4).

Comparison with SEER database. Based on a comparison of the age- and sex-specific incidence rate for solid malignancies in the SEER database, 1.92 solid malignancies would have been expected in the etaner- 
Table 4. Treatment with immunosuppression before and during the WGET*

\begin{tabular}{|c|c|c|c|c|}
\hline & $\begin{array}{l}\text { Control } \\
(\mathrm{n}=91)\end{array}$ & $\begin{array}{l}\text { Etanercept } \\
(\mathrm{n}=89)\end{array}$ & $\begin{array}{c}\text { Total } \\
(\mathrm{n}=180)\end{array}$ & $\begin{array}{c}P, \text { control vs. } \\
\text { etanercept }\end{array}$ \\
\hline \multicolumn{5}{|l|}{ Before trial enrollment } \\
\hline \multicolumn{5}{|l|}{ CYC treatment } \\
\hline Ever used, daily or intermittent, no. (\%) & $62(68.1)$ & $70(78.7)$ & $132(73.3)$ & 0.111 \\
\hline Daily CYC ever used, no. (\%) & $60(65.9)$ & $66(74.2)$ & $126(70.0)$ & 0.229 \\
\hline Daily CYC duration, median (IQR) days & $73(14-333)$ & $60(27-303)$ & $70(18-303)$ & 0.299 \\
\hline Daily CYC maximum dosage, mean \pm SD mg & $151.5 \pm 48.4$ & $140.2 \pm 39.4$ & $145.4 \pm 44.0$ & 0.281 \\
\hline Intermittent CYC ever used, no. (\%) & $8(8.8)$ & $12(13.5)$ & $20(11.1)$ & 0.317 \\
\hline Intermittent CYC duration, median (IQR) days & $4(3-56)$ & $75(7-365)$ & $30(4-240)$ & 0.174 \\
\hline Intermittent $\mathrm{CYC}$ maximum dose, mean $\pm \mathrm{SD}$ mg & $910.0 \pm 450.6$ & $986.3 \pm 484.8$ & $962.5 \pm 460.6$ & 0.953 \\
\hline \multicolumn{5}{|l|}{ MTX treatment } \\
\hline Ever used, oral or SC or IM, no. (\%) & $31(34.1)$ & $36(40.5)$ & $67(37.2)$ & 0.376 \\
\hline Oral MTX ever used, no. (\%) & $29(31.9)$ & $34(38.2)$ & $63(35.0)$ & 0.373 \\
\hline Oral MTX duration, median (IQR) days & $429(83-774)$ & $208(35-936)$ & $300(55-788)$ & 0.298 \\
\hline Oral MTX maximum dosage, mean \pm SD mg & $17.6 \pm 6.3$ & $17.6 \pm 4.7$ & $17.6 \pm 5.4$ & 0.723 \\
\hline SC or IM MTX ever used, no. (\%) & $8(8.8)$ & $12(13.5)$ & $20(11.1)$ & 0.317 \\
\hline SC or IM MTX duration, median (IQR) days & $465(135-730)$ & $197(85-624)$ & $222(90-715)$ & 0.487 \\
\hline $\mathrm{SC}$ or IM MTX maximum dose, mean $\pm \mathrm{SD}$ mg & $23.1 \pm 5.6$ & $23.3 \pm 3.9$ & $23.3 \pm 4.5$ & 0.516 \\
\hline AZA treatment, ever used, no. (\%) & $9(9.9)$ & $12(13.5)$ & $21(11.7)$ & 0.453 \\
\hline \multicolumn{5}{|l|}{ During trial } \\
\hline \multicolumn{5}{|l|}{ Experimental treatment } \\
\hline Time, median (IQR) months & $19(13-33)$ & $25(12-33)$ & $21(13-33)$ & 0.875 \\
\hline \multirow{2}{*}{\multicolumn{5}{|c|}{ CYC treatment }} \\
\hline & & & & \\
\hline During WGET, no. (\%) & $73(80.2)$ & $68(76.4)$ & $141(78.3)$ & 0.535 \\
\hline Time, median (IQR) months $\dagger$ & $6(3-10)$ & $6(5-10)$ & $6(5-10)$ & 0.660 \\
\hline No. of interruptions, mean \pm SD & $1.0 \pm 0.9$ & $1.2 \pm 1.0$ & $1.1 \pm 0.9$ & 0.486 \\
\hline Cumulative dose, median (IQR), $\mathrm{mg} \times 10^{3} \ddagger$ & $18(11-32)$ & $19(8-29)$ & $19(9-30)$ & 0.901 \\
\hline \multicolumn{5}{|l|}{ MTX treatment } \\
\hline During WGET, no. $(\%)$ & $72(79.1)$ & $65(73.0)$ & $137(76.1)$ & 0.338 \\
\hline Time, median (IQR) months $\dagger$ & $16(9-25)$ & $17(10-25)$ & $17(10-25)$ & 0.779 \\
\hline No. of interruptions, mean \pm SD & $0.8 \pm 1.0$ & $0.8 \pm 0.8$ & $0.8 \pm 0.9$ & 0.484 \\
\hline Cumulative dose, median (IQR) $\mathrm{mg} \times 10^{2} \ddagger$ & $13(5-24)$ & $14(6-25)$ & $13(5-24)$ & 0.620 \\
\hline \multicolumn{5}{|l|}{ AZA treatment } \\
\hline During WGET, no. (\%) & $22(24.2)$ & $28(31.5)$ & $50(27.8)$ & 0.275 \\
\hline Time, median (IQR) months $\dagger$ & $9(5-15)$ & $14(5-21)$ & $12(5-18)$ & 0.233 \\
\hline No. of interruptions, mean \pm SD & $1.1 \pm 1.2$ & $0.9 \pm 0.9$ & $1.0 \pm 1.0$ & 0.583 \\
\hline Cumulative dose, median (IQR) $\mathrm{mg} \times 10^{3} \ddagger$ & $21(7-47)$ & $24(4-41)$ & $24(6-47)$ & 0.701 \\
\hline
\end{tabular}

$*$ CYC $=$ cyclophosphamide; MTX = methotrexate; AZA = azathioprine (see Table 3 for other definitions).

† Start and end dates for treatment are not precise. Start date is the date of the previous visit for the first form indicating that treatment had been received since the previous visit. End date is the form date for the last consecutive form indicating that treatment had been received since the previous visit. Treatment may not have been received continuously between visits.

$\$$ Patients with missing dose at any visit have missing cumulative dose data.

cept group, whereas 6 occurred (standardized incidence ratio 3.12 [95\% confidence interval 1.15-6.80]; $P=$ $0.014)$.

\section{DISCUSSION}

In the WGET, 6 of the 89 patients randomized to receive etanercept $(7 \%)$ developed solid malignancies over a median followup period of just over 2 years, during which time no solid malignancies occurred in the placebo group. In the 6-month observation period that followed the cessation of experimental treatment, 2 additional solid malignancies were diagnosed in patients who had received treatment with a TNF inhibitor, and 1 was observed in a patient who had not received TNF inhibition treatment. Of note, all 6 of the patients with solid malignancies detected during the trial and 8 of the 9 patients overall who developed solid malignancies were also treated with cyclophosphamide during the trial. These results suggest that the combination of TNF inhibition and cyclophosphamide may heighten the risk of cancer beyond the risk observed with cyclophosphamide treatment alone. The WGET is the first trial in which a substantial number of patients were treated with both TNF inhibition and cyclophosphamide. Although the absolute number of patients who developed solid malignancies in this trial is small, 
current understanding of the biology of TNF suggests that these findings warrant further exploration.

A significant body of literature supports the concept that TNF is active against some forms of cancer. In the 1970s, Carswell et al recognized that the treatment of mice with lipopolysaccharide and BCG led to the production of "tumor necrosis factor," an endogenous molecule that induced tumor cell death in a variety of in vitro and mouse models (6). Experimental evidence of an antitumor effect of TNF led to the systemic administration of this cytokine for the treatment of advanced solid tumors (23-27). The activity of TNF against tumors in laboratory models, and potentially in humans as well, raises the possibility that inhibition of this cytokine might potentiate the clinical risk of malignancy.

The possible association between TNF inhibition and lymphoma has received considerable scrutiny $(8,9)$. The incidence of non-Hodgkin's lymphoma in randomized controlled trials of TNF inhibitors was compared with the number of lymphomas reported in the NIH SEER database, yielding standardized incidence ratios of 2.3-3.5 for etanercept, 6.4 for infliximab, and 5.5 for adalimumab (11). Analyses of the true nature of the reported associations between TNF inhibitors and lymphoma, however, have been hampered by a variety of confounding factors. Patients with RA appear to have an underlying predisposition to lymphoma development (7), and this predisposition is greater among patients with higher levels of disease activity-precisely the group that receives TNF inhibitors. Moreover, some medications used to treat RA, particularly methotrexate, are also believed to increase the risk of lymphoma (28). Nevertheless, the labels of the 3 anti-TNF agents on the market all bear warnings about a potentially increased risk (up to severalfold) for the development of lymphoma.

Our study has a number of important strengths. First, the trial provided longitudinal followup of the largest cohort of patients with WG studied in a clinical trial to date. Second, the data on the occurrence of malignancy were collected during a blinded clinical trial. An audit of trial data did not reveal any additional solid malignancies (Amgen Corporation: unpublished data). Third, these data represent by far the largest report of the simultaneous use of TNF inhibition and cyclophosphamide treatment.

It is therefore not surprising that the potential relationship between TNF inhibition, concomitant cyclophosphamide use, and malignancy has not been recog- nized previously. As illustrated by the recent findings of a relationship between cyclooxygenase 2 inhibition and adverse cardiovascular events (29), the system of voluntary reporting of postmarketing adverse events is reasonably effective at detecting rare events, but less so for detecting relatively common ones (30). Because most of the solid malignancies observed in the WGET are common types of cancer, it is conceivable that any increased risk of such tumors among patients taking TNF inhibitors might be difficult to detect. This is particularly true for the combination of TNF inhibitors and other medications known to increase the risk of cancer. Outside the context of a randomized trial that involved careful comparison of a group that received etanercept and one that received standard therapy alone, the observed association between etanercept and solid malignancies would probably have been overlooked.

Our study also has potential weaknesses. Interpretation of the increased number of malignancies in the etanercept group during the WGET is complicated by potential confounders. First, owing to chance in the process of randomization, patients in the etanercept group were 4.9 years older on average than those in the placebo group. Second, patients in the etanercept group were also less likely to have newly diagnosed WG at the time of trial enrollment, and therefore their risk of cancer could conceivably have been influenced by treatment prior to enrollment in the WGET. Third, there have been reports that WG itself, like RA, may be associated with an increased risk of cancer (31-35). After accounting for patient age and sex in a comparison with the SEER database, however, the standardized incidence ratio for the development of solid malignancy was found to be significantly elevated in the etanercept group (3.12). Moreover, although patients in the etanercept group were less likely to be newly diagnosed as having WG, their history of cyclophosphamide exposure both before and during the WGET was not different from that of patients in the placebo group. Finally, because patients in both the etanercept and the placebo groups had diagnoses of WG, any increased risk of malignancy associated with that diagnosis would be irrelevant for the purpose of this analysis.

The findings in this study have several potential implications, even though the number of malignancies observed-still relatively small-precludes definitive conclusions on any relationship between TNF inhibition treatment, cyclophosphamide treatment, and the development of malignancy. In patients with inflammatory disease, prescription of medications off-label, and of 
combinations of treatments that have not been tested adequately in clinical trials, is not uncommon. The observation of an increased risk of solid malignancies among patients in the etanercept group raises a cautionary flag, particularly with regard to the combination of TNF inhibition and cyclophosphamide. These findings are particularly relevant, for example, to patients with systemic lupus erythematosus, many of whom have been treated with cyclophosphamide in the past. The findings are also pertinent to patients with rheumatoid vasculitis, who often receive cyclophosphamide and who may also be treated with TNF inhibitors.

Finally, this report emphasizes the importance of long-term followup of patients treated with TNF inhibition and concomitant immunosuppressive medications. It is conceivable that the combination of cyclophosphamide and TNF inhibition accelerates a process of oncogenesis that may be recognized only over the longer term in patients treated with TNF inhibition alone. To date, no concerns about solid malignancies developing after long-term therapy have emerged from longitudinally studied TNF inhibitor-treated cohorts, but data sets on patients treated for years with these approaches remain small compared with the total number of patients treated for any period of time.

In conclusion, data from the WGET, the first substantial reported experience of the combined use of etanercept and cyclophosphamide, indicate that the combination of TNF inhibition and cyclophosphamide may heighten the risk of cancer beyond that observed with cyclophosphamide alone. The addition of TNF inhibitors to potent immunosuppressive treatment regimens may increase the risk of solid tumors. These findings should be considered in the design of future studies and in decisions regarding off-label use of TNF inhibition.

\section{REFERENCES}

1. Maini SR. Infliximab treatment of rheumatoid arthritis. Rheum Dis Clin North Am 2004;30:329-47.

2. Olsen NJ, Stein CM. New drugs for rheumatoid arthritis. N Engl J Med 2004;350:2167-79.

3. Sands BE, Anderson FH, Bernstein CN, Chey WY, Feagan BG, Fedorak RN, et al. Infliximab maintenance therapy for fistulizing Crohn's disease. N Engl J Med 2004;350:876-85.

4. Gorman JD, Sack KE, Davis JC Jr. Treatment of ankylosing spondylitis by inhibition of tumor necrosis factor $\alpha$. N Engl J Med 2002;346:1349-56.

5. Leonardi CL, Powers JL, Matheson RT, Goffe BS, Zitnik R, Wang A, et al. Etanercept as monotherapy in patients with psoriasis. N Engl J Med 2003;349:2014-22.

6. Carswell EA, Old LJ, Kassel RL, Green S, Fiore N, Williamson B
An endotoxin-induced serum factor that causes necrosis of tumors. Proc Natl Acad Sci U S A 1975;72:3666-70.

7. Symmons DP, Silman AJ. Anti-tumor necrosis factor $\alpha$ therapy and the risk of lymphoma in rheumatoid arthritis: no clear answer [editorial]. Arthritis Rheum 2004;50:1703-6.

8. Brown SL, Greene MH, Gershon SK, Edwards ET, Braun MM. Tumor necrosis factor antagonist therapy and lymphoma development: twenty-six cases reported to the Food and Drug Administration. Arthritis Rheum 2002;46:3151-8.

9. Wolfe F, Michaud K. Lymphoma in rheumatoid arthritis: the effect of methotrexate and anti-tumor necrosis factor therapy in 18,572 patients. Arthritis Rheum 2004;50:1740-51.

10. Surveillance Epidemiology and End Results (SEER) Program. SEER*Stat Database: Incidence-SEER 9 regs public use, Nov 2002 sub (1973-2000). National Cancer Institute, DCCPS, Surveillance Research Program, Cancer Statistics Branch. Released April 2003.

11. FDA Arthritis Advisory Committee Meeting, 3/04. URL: http:// www.fda.gov/ohrms/dockets/ac/cder03.html\#Arthritis.

12. Bakland G, Nossent $\mathrm{H}$. Acute myelogenous leukaemia following etanercept therapy. Rheumatology (Oxford) 2003;42:900-1.

13. Alcain G, Andrade RJ, Queipo de Llano MP, Moreno MJ, Garcia-Cortes M, Franquelo E. Acute leukemia after infliximab therapy [letter]. Am J Gastroenterol 2003;98:2577.

14. Mahe E, Descamps V, Grossin M, Fraitag S, Crickx B. CD30+ T-cell lymphoma in a patient with psoriasis treated with ciclosporin and infliximab. Br J Dermatol 2003;149:170-3.

15. Smith KJ, Skelton HG. Rapid onset of cutaneous squamous cell carcinoma in patients with rheumatoid arthritis after starting tumor necrosis factor $\alpha$ receptor IgG1-Fc fusion complex therapy. J Am Acad Dermatol 2001;45:953-6.

16. Esser AC, Abril A, Fayne S, Doyle JA. Acute development of multiple keratoacanthomas and squamous cell carcinomas after treatment with infliximab. J Am Acad Dermatol 2004;50(5 Suppl): S75-7.

17. Cohen CD, Horster S, Sander CA, Bogner JR. Kaposi's sarcoma associated with tumor necrosis factor $\alpha$ neutralizing therapy [letter]. Ann Rheum Dis 2003;62:684.

18. The WGET Research Group. Etanercept in addition to standard therapy in patients with Wegener's granulomatosis. N Engl J Med 2005;352:351-61.

19. The WGET Research Group. Design of the Wegener's Granulomatosis Etanercept Trial (WGET). Control Clin Trials 2002;23: 450-68.

20. The Wegener's Granulomatosis Etanercept Trial Research Group. Limited versus severe Wegener's granulomatosis: baseline data on patients in the Wegener's Granulomatosis Etanercept Trial. Arthritis Rheum 2003;48:2299-309.

21. Stone JH, Hoffman GS, Merkel PA, Min YI, Uhlfelder ML, Hellmann DB, et al. A disease-specific activity index for Wegener's granulomatosis: modification of the Birmingham Vasculitis Activity Score. Arthritis Rheum 2001;44:912-20.

22. National Cancer Institute. Toxicity Grading Scale. URL: http:// ctep.info.nih.gov.

23. Creagan ET, Ahmann DL, Frytak S, Long HJ, Chang MN, Itri LM. Three consecutive phase II studies of recombinant interferon alfa-2a in advanced malignant melanoma: updated analyses. Cancer 1987;59(3 Suppl):638-46.

24. Feldman AL, Alexander HR Jr, Bartlett DL, Fraker DL, Libutti SK. Management of extremity recurrences after complete responses to isolated limb perfusion in patients with melanoma. Ann Surg Oncol 1999;6:562-7.

25. Spriggs DR, Sherman ML, Michie H, Arthur KA, Imamura K, Wilmore D, et al. Recombinant human tumor necrosis factor administered as a 24-hour intravenous infusion: a phase I and pharmacologic study. J Natl Cancer Inst 1988;80:1039-44.

26. Muggia FM, Brown TD, Goodman PJ, Macdonald JS, Hersh EM, 
Fleming TR, et al. High incidence of coagulopathy in phase II studies of recombinant tumor necrosis factor in advanced pancreatic and gastric cancers. Anticancer Drugs 1992;3:211-7.

27. Lejeune FJ, Ruegg C, Lienard D. Clinical applications of TNF- $\alpha$ in cancer. Curr Opin Immunol 1998;10:573-80.

28. Ebeo CT, Girish MR, Byrd RP, Roy TM, Mehta JB. Methotrexate-induced pulmonary lymphoma. Chest 2003;123:2150-3.

29. Finckh A, Aronson MD. Cardiovascular risks of cyclooxygenase-2 inhibitiors: where we stand now. Ann Intern Med 2005;142: $157-64$.

30. Okie S. Safety in numbers: monitoring risk in approved drugs. N Engl J Med 2005;352:1173-6.

31. Pankhurst T, Savage CO, Gordon C, Harper L. Malignancy is increased in ANCA-associated vasculitis. Rheumatology (Oxford) 2004;43:1532-5.

32. Westman KW, Bygren PG, Olsson H, Ranstam J, Wieslander J. Relapse rate, renal survival, and cancer morbidity in patients with Wegener's granulomatosis or microscopic polyangiitis with renal involvement. J Am Soc Nephrol 1998;9:842-52.

33. Knight A, Askling J, Ekbom A. Cancer incidence in a populationbased cohort of patients with Wegener's granulomatosis. Int J Cancer 2002;100:82-5.

34. Knight A, Askling J, Granath F, Sparen P, Ekbom A. Urinary bladder cancer in Wegener's granulomatosis: risks and relation to cyclophosphamide. Ann Rheum Disease 63:1307-11.

35. Tatsis E, Reinhold-Keller E, Steindorf K, Feller AC, Gross WL. Wegener's granulomatosis associated with renal cell carcinoma. Arthritis Rheum 1999;42:751-6.

\section{APPENDIX A: THE WGET RESEARCH GROUP}

The Chairman of the WGET Research Group is John H. Stone, MD, MPH (The Johns Hopkins Vasculitis Center) and the Co-Chairman is Gary S. Hoffman, MD, MS (The Cleveland Clinic Foundation Center for Vasculitis Research and Care). The Coordinating Center is The Johns Hopkins University Center for Clinical Trials (Janet T. Holbrook, PhD, MPH, Director; Curtis L. Meinert,
$\mathrm{PhD}$, Associate Director; John Dodge, Systems Analyst; Jessica Donithan, Research Coordinator; Y.-I. Min, PhD, Biostatistician; Laurel Murrow, MSc, Trial Coordinator [former]; Maria Oziemkowska, MPH Trial Coordinator [former]; Jacki Smith, Research Data Assistant; Andrea K. Tibbs, BS, Trial Coordinator; Mark Van Natta, MHS, Biostatistician). The Resource Center is The Johns Hopkins University Immune Diseases Laboratory (Noel R. Rose, MD, PhD; C. Lynne Burek, PhD; Jobert Barin, BS; Monica Taylor, MS). Members of the Data Safety and Monitoring Board are John H. Klippel, MD, Arthritis Foundation, Atlanta, Georgia (Chair); Paul L. Canner, PhD, Maryland Medical Research Institute, Baltimore; Doyt L. Conn, MD, Emory University, Atlanta, Georgia (Safety Officer); and J. Richard Landis, PhD, University of Pennsylvania, Philadelphia.

Investigators at the participating clinical centers are as follows: The Beth Israel Medical Center, New York, New York, Robert Spiera, MD, Iresha Abeynayake, MPH, Rosanne Berman, MPH, and Sandy Enuha, MPH; Boston University, Boston, Massachusetts, Peter A. Merkel, MD, MPH, Rondi Gelbard, BS, Melynn Nuite, RN, and Aileen Schiller, MS; The Cleveland Clinic Foundation, Cleveland, Ohio, Gary S. Hoffman, MD, MS, David Blumenthal, MD, Debora Bork, MFA, Leonard H. Calabrese, DO, Tiffany Clark, CNP, Sonya L. Crook, RN, Sharon Farkas, Sudhakar Sridharan, MD, Kimberly Strom, CNP, and William Wilke, MD; Duke University, Durham, North Carolina, E. William St.Clair, MD, Nancy B. Allen, MD, Karen Rodin, RN, and Edna Scarlett; The Johns Hopkins University, Baltimore, Maryland, John H. Stone, MD, MPH, David B. Hellmann, MD, Matthew A. Marriott, PA-C, Amanda M. Moore, BS, Lourdes Pinachos, RN, BSN, Michael J. Regan, MD, MRCP, and Misty L. Uhlfelder, MPH; The Mayo Clinic, Rochester, Minnesota, Ulrich Specks, MD, Kristin Bradt, Kimberly Carlson, Susan Fisher, RN, Boleyn Hammel, Kathy Mieras, and Steven Ytterberg, MD; the University of California, San Francisco, John C. Davis, MD, MPH, Anne Marie Duhme, BSN, Maureen Fitzpatrick, MPH, Ken Fye, MD, and Steve Lund, MSN, NP; the University of Michigan, Ann Arbor, Joseph McCune, MD, Billie Jo Coomer, BS, Barbara Gilson, RN, Hilary Haftel, MD, Ana Morrel-Samuels, BA, and Sandra Neckel, RN. 